- In 2005 more patients presenting to dental practice were taking medications compared to 1984.

- There is an increasing trend toward polypharmacy.

- Patients receiving multiple medications have been reported to suffer more adverse effects of dental local anaesthesia.

- An increase in the number and range of medications taken by patients increases the risk of drug interactions with medication that dentists may prescribe.

- Maintaining a contemporaneous knowledge of pharmacology and drug interaction ensures the provision of safe dental care.

\title{
Prescribed medication taken by patients attending general dental practice: changes over 20 years
}

\author{
L. M. Carter, ${ }^{1}$ I. D. S. McHenry, ${ }^{2}$ F. L. Godlington ${ }^{3}$ and J. G. Meechan ${ }^{4}$
}

Introduction Drug therapy can influence treatment planning and provision of dental care by general dental practitioners. There is little published information regarding the types of drug therapy taken by patients presenting for dental treatment in the United Kingdom. Objective To record the drug therapy taken by patients presenting to general dental practice in 1995 and 2005 and compare to data reported in 1984.

Setting General dental practice.

Study design Prospective cross-sectional study.

Method Patients presenting to general dental practices in 1995 and 2005 were questioned regarding their current drug therapy. Patients' general medical practitioners were contacted if their drug history was unclear.

Results $35 \%, 21.1 \%$ and $43.8 \%$ of patients were taking medications in 1984, 1995 and 2005 respectively. Statistically significant increases in the proportion taking three or more medications were evident in both 1995 and 2005.

Discussion In 2005 more patients presenting to dental practice were taking medications compared to 1984. There is an increasing trend toward polypharmacy. Therefore it is important to maintain a contemporaneous knowledge of pharmacology and drug interactions to ensure the provision of safe dental care.

\footnotetext{
1"Specialist Registrar, Department of Oral and Maxillofacial Surgery, ${ }^{2}$ Senior House Officer, Department of Oral and Maxillofacial Surgery, Leeds Dental Institute, Clarendon Way, Leeds, LS2 9LU; ${ }^{3}$ General Dental Practitioner, Dental Surgery, 242 The Broadway, North Shields, NE30 3DB: ${ }^{4}$ Senior Lecturer, Department of Oral Surgery, School of Dental Sciences, University of Newcastle upon Tyne, Framlington Place, Newcastle upon Tyne, NE2 4BZ

*Correspondence to: Mr Lachlan M. Carter

Email: lachlan_carter@hotmail.com
}

\section{Online article number E8}

Refereed Paper - accepted 24 January 2007

DOI: $10.1038 /$ bdj.2007.629

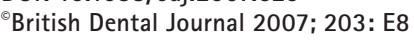

\section{INTRODUCTION}

Drug therapy can influence treatment planning and the provision of dental care by general dental practitioners. In addition, drug therapy can produce adverse effects on oral structure and function, for example lichenoid reactions and dry mouth. There is little information regarding the types of drug therapy taken by patients presenting to general dental practices for treatment in the United Kingdom. This information is not only essential for safe clinical practice but is also invaluable for planning undergraduate and postgraduate teaching in clinical pharmacology, and in monitoring future trends in therapeutics. This study therefore investigated the drug therapy taken by patients attending general dental practices in the United Kingdom in 1995 and 2005.

\section{METHOD}

One hundred and ninety-nine consecutive patients attending a general dental practice in North Shields, Northumberland in 1995 and 500 consecutive patients attending a general dental practice in Cleckheaton, West Yorkshire in 2005 were prospectively questioned regarding their current medication at the time of presentation. The names of all current medications taken were obtained by direct questioning. The patient's general medical practitioner was contacted if the patient's medication was unknown or unclear.

The medications were classified according to the British National Formulary 52. ${ }^{1}$ The data obtained were compared to data reported by Hemsley in $1984 .^{2}$ Hemsley's paper reported data obtained from two general dental practices in Kent. Data analysis was performed using chi-square and Student's t tests.

\section{RESULTS}

Table 1 shows the age and gender distribution of those questioned. There was no significant difference in gender distribution between the groups. No age-related data were published by Hemsley in $1984 ;^{2}$ however there was no significant 


\begin{tabular}{|c|c|c|c|}
\hline & 1984 & 1995 & 2005 \\
\hline Total patients & 500 & 199 & 500 \\
\hline Male & $227(45.4 \%)$ & $95(47.7 \%)$ & $240(48 \%)$ \\
\hline \multirow[t]{2}{*}{ Female } & $273(54.6 \%)$ & $104(52.3 \%)$ & $260(52 \%)$ \\
\hline & \multicolumn{3}{|c|}{$\left(\chi^{2}=0.75, d f=2, p=0.6872\right)$} \\
\hline Mean age & $N / A$ & 49.9 & 51.0 \\
\hline Standard deviation & N/A & \pm 16.3 & \pm 19.5 \\
\hline \multirow[t]{2}{*}{ Range } & N/A & $14-94$ & $7-95$ \\
\hline & \multicolumn{3}{|c|}{$(\mathrm{t}=-0.74, \mathrm{p}=0.4558,95 \% \mathrm{Cl}-3.9-1.8)$} \\
\hline \multirow[t]{2}{*}{$\begin{array}{l}\text { Percentage taking } \\
\text { medication }\end{array}$} & $35.0 \%$ & $21.1 \%$ & $43.8 \%$ \\
\hline & \multicolumn{3}{|c|}{$\left(x^{2}=32.371, d f=2, p=0.0027\right)$} \\
\hline
\end{tabular}

Table 2 Numbers of medications taken

\begin{tabular}{|l|l|l|l|}
\hline $\begin{array}{l}\text { Number of } \\
\text { medications }\end{array}$ & 1984 & 1995 & 2005 \\
\hline 0 & 325 & 157 & 281 \\
\hline 1 & 133 & 24 & 94 \\
\hline 2 & 31 & 11 & 48 \\
\hline 3 or more & 11 & 7 & 77 \\
\hline$\left(x^{2}=93.929, d f=6, p<0.0001\right)$ & & \\
\hline
\end{tabular}

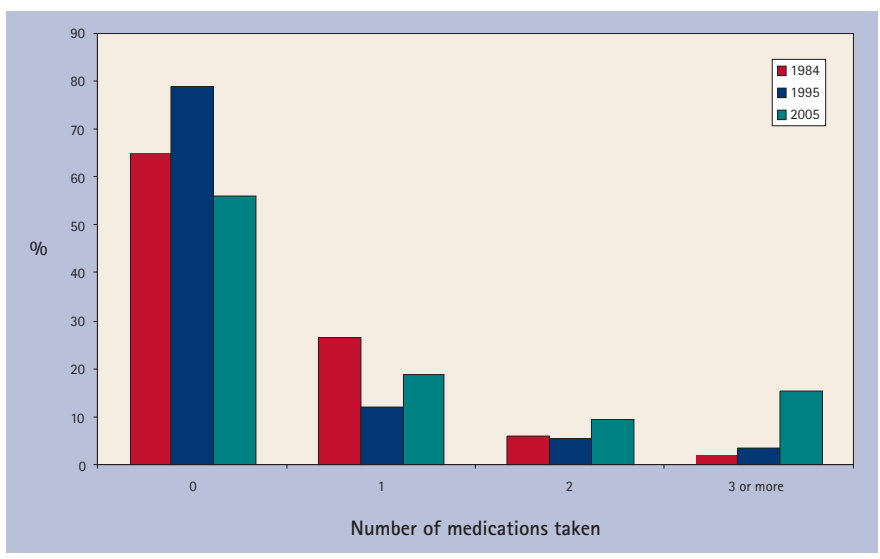

Fig. 1 Distribution of the number of medications taken (percentage)

difference in age distribution between the groups from 1995 and 2005. Table 1 also shows the percentage taking medication for each group.

Compared to 1984 , significantly fewer patients were taking medication in 1995 whereas significantly more patients were taking medication in 2005. Table 2 shows the number of medications taken for each group. The number of medications taken is illustrated as a percentage in Figure 1 which shows that of those taking medications, the percentage taking three or more medications significantly increased from 1984 to 2005.

Figure 2 and Table 3 show the number and percentage of the types of medication taken. The types of medication are expressed as a percentage of the total number of medications taken. An increase in the use of cardiovascular, endocrine and musculoskeletal medications is demonstrated. Compared to 1984 , there are notable increases in the proportion taking nitrates and calcium channel blockers, anticoagulants, antiplatelet drugs, lipid regulators, bronchodilators and inhaled corticosteroids. There are notable decreases in the proportion taking hypnotics and anxiolytics, and contraceptives.

\section{DISCUSSION}

When comparing 1984 to 2005 the percentage of patients taking medications has increased, although there was a reduction in the proportion of patients taking prescribed drugs in the 1995 sample. There is an increasing trend toward polypharmacy. There were statistically significant increases in the proportion taking three or more medications in both 1995 and 2005 compared to 1984. Polypharmacy impacts on the provision of dental care, for example it has been demonstrated that patients receiving multiple medications are more likely to suffer adverse effects when being treated under local anaesthesia. ${ }^{3}$

There is a greater range of medications taken by patients in 2005. The changes in distribution of the type of therapy taken will clearly influence clinical practice: the increase in the proportion taking anticoagulants and antiplatelet drugs will affect procedures with significant risk of haemorrhage, such as exodontia. The increase in the proportion taking inhaled corticosteroids may lead to a greater number presenting with oral candidiasis. Increased therapy with cardiovascular drugs may lead to greater prevalence of oral side-effects such as dry mouth and lichenoid reactions. The changes in the distribution and the greater range of medications taken may be explained by the development of new medications and their introduction into clinical practice over time.

This study compares three geographically disparate populations, although there was no statistically significant difference in the sex distribution between the three groups. The 1995 and 2005 groups showed a similar age distribution. The groups are therefore comparable in terms of age and sex but the geographically different populations may have differing health needs and different levels of health awareness. The prescribing habits of general medical practitioners and hospital doctors may vary and also diagnostic capabilities may have improved with time, which again may have lead to inaccuracy when comparing the groups. The smaller sample size in 1995 may have also contributed to inaccuracy. Lack of patients' willingness to volunteer information could also have lead to imprecision, as patients may not have wanted their dentist to know about the use of certain types of medication, such as contraceptives.

Haskell reported that knowledge of drugs of dental importance was imperative and suggested a limited number of medications that a general dental practitioner should be familiar with. ${ }^{4}$ The number of medications that can affect oral health and affect the delivery of dental care is wide ranging. Therefore knowledge of pharmacology should not be limited. ${ }^{5}$

This study shows that more patients presenting to dental practices are taking medication now compared to 1984 and that there is an increasing trend toward polypharmacy. An increase in the number and range of medications taken increases the risk of drug interactions with medication that dentists may prescribe. ${ }^{6,7}$ Although beyond the scope of this paper, it is 
Table 3 Types of medication taken

\begin{tabular}{|c|c|c|c|c|c|c|c|}
\hline \multirow{2}{*}{$\begin{array}{l}\text { BNF } \\
\text { category }\end{array}$} & \multirow{2}{*}{ Drug types } & \multicolumn{2}{|c|}{1984} & \multicolumn{2}{|c|}{1995} & \multicolumn{2}{|c|}{2005} \\
\hline & & $\mathrm{n}$ & $\%(N=229)$ & $n$ & $\%(N=72)$ & $\mathrm{n}$ & $\%(N=531)$ \\
\hline 1 & \multicolumn{7}{|l|}{ Gastro-intestinal system } \\
\hline 1.1 & Dyspepsia & 0 & 0 & 0 & 0 & 1 & 0.19 \\
\hline 1.2 & Antispasmodics & 0 & 0 & 2 & 2.78 & 1 & 0.19 \\
\hline 1.3 & Ulcer healing drugs & 5 & 2.18 & 3 & 4.17 & 4 & 0.75 \\
\hline 1.4 & Acute diarrhoea & 0 & 0 & 0 & 0 & 1 & 0.19 \\
\hline 1.5 & Chronic bowel disorders & 1 & 0.43 & 0 & 0 & 2 & 0.38 \\
\hline 1.6 & Laxatives & 3 & 1.31 & 0 & 0 & 2 & 0.38 \\
\hline 2 & \multicolumn{7}{|l|}{ Cardiovascular system } \\
\hline 2.1 & Positive inotropics & 1 & 0.43 & 0 & 0 & 4 & 0.75 \\
\hline 2.2 & Diuretics & 13 & 5.68 & 1 & 1.39 & 36 & 6.78 \\
\hline 2.3 & Anti-arrhythmics & 3 & 1.31 & 0 & 0 & 1 & 0.19 \\
\hline 2.4 & Beta blockers & 22 & 9.61 & 8 & 11.11 & 37 & 6.97 \\
\hline 2.5 & Hypertension and heart failure & 9 & 3.93 & 1 & 1.39 & 34 & 6.40 \\
\hline 2.6 & Nitrates, calcium channel blockers & 0 & 0 & 15 & 20.83 & 52 & 9.79 \\
\hline 2.8 & Anticoagulants & 1 & 0.43 & 3 & 4.17 & 9 & 1.69 \\
\hline 2.9 & Antiplatelet drugs & 4 & 1.75 & 6 & 8.33 & 44 & 8.29 \\
\hline 2.12 & Lipid regulators & 0 & 0 & 0 & 0 & 59 & 11.11 \\
\hline 3 & \multicolumn{7}{|l|}{ Respiratory system } \\
\hline 3.1 & Bronchodilators & 5 & 2.18 & 9 & 12.50 & 31 & 5.83 \\
\hline 3.2 & Inhaled corticosteroids & 0 & 0 & 7 & 9.72 & 20 & 3.77 \\
\hline 3.3 & Leukotriene receptor antagonists & 0 & 0 & 0 & 0 & 1 & 0.19 \\
\hline 3.4 & Antihistamines & 2 & 0.87 & 0 & 0 & 6 & 1.13 \\
\hline 4 & \multicolumn{7}{|l|}{ Central nervous system } \\
\hline 4.1 & Hypnotics and anxiolytics & 21 & 9.17 & 1 & 1.39 & 4 & 0.75 \\
\hline 4.2 & Psychoses and related disorders & 3 & 1.31 & 2 & 2.78 & 5 & 0.94 \\
\hline 4.3 & Antidepressants & 8 & 3.49 & 0 & 0 & 19 & 3.58 \\
\hline 4.4 & CNS stimulants & 1 & 0.43 & 0 & 0 & 0 & 0 \\
\hline 4.6 & Nausea and vertigo & 3 & 1.31 & 1 & 1.39 & 3 & 0.56 \\
\hline 4.7 & Analgesics & 19 & 8.30 & 0 & 0 & 35 & 6.59 \\
\hline 4.8 & Anti-epileptics & 9 & 3.93 & 2 & 2.78 & 2 & 0.38 \\
\hline 4.9 & Anti-Parkinsonian & 1 & 0.43 & 0 & 0 & 0 & 0 \\
\hline 4.10 & Substance dependence & 0 & 0 & 0 & 0 & 1 & 0.19 \\
\hline 4.11 & Drugs for dementia & 0 & 0 & 0 & 0 & 1 & 0.19 \\
\hline 5 & \multicolumn{7}{|l|}{ Infections } \\
\hline 5.1 & Anti-bacterials & 22 & 9.61 & 1 & 1.39 & 5 & 0.94 \\
\hline 6 & \multicolumn{7}{|l|}{ Endocrine system } \\
\hline 6.1 & Drugs used in diabetes & 3 & 1.31 & 1 & 1.39 & 11 & 2.07 \\
\hline 6.2 & Thyroid and anti-thyroid drugs & 8 & 3.49 & 0 & 0 & 17 & 3.20 \\
\hline 6.3 & Corticosteroids & 5 & 2.18 & 0 & 0 & 9 & 1.69 \\
\hline 6.4 & Sex hormones & 2 & 0.87 & 3 & 4.17 & 10 & 1.88 \\
\hline 6.6 & Drugs affecting bone metabolism & 0 & 0 & 0 & 0 & 2 & 0.38 \\
\hline
\end{tabular}




\section{RESEARCH}

\begin{tabular}{|c|c|c|c|c|c|c|c|}
\hline \multicolumn{8}{|c|}{ Continued from page 3} \\
\hline 7 & \multicolumn{7}{|l|}{ Obstetrics and gynaecology } \\
\hline 7.3 & Contraceptives & 20 & 8.73 & 2 & 2.78 & 11 & 2.07 \\
\hline 7.4 & Urinary frequency & 0 & 0 & 0 & 0 & 1 & 0.19 \\
\hline 8 & \multicolumn{7}{|l|}{ Malignant disease and immunosuppression } \\
\hline 8.1 & Cytotoxic & 4 & 1.75 & 0 & 0 & 2 & 0.38 \\
\hline 8.3 & $\begin{array}{l}\text { Sex hormones and hormone antagonists in } \\
\text { malignant disease }\end{array}$ & 0 & 0 & 0 & 0 & 3 & 0.56 \\
\hline 9 & \multicolumn{7}{|l|}{ Nutrition and blood } \\
\hline 9.1 & Anaemias & 13 & 5.68 & 0 & 0 & 5 & 0.94 \\
\hline 9.5 & Minerals & 21 & 9.17 & 0 & 0 & 1 & 0.19 \\
\hline 9.6 & Vitamins & 7 & 3.06 & 0 & 0 & 1 & 0.19 \\
\hline 10 & \multicolumn{7}{|l|}{ Musculoskeletal and joint disease } \\
\hline 10.1 & Rheumatic disease and gout & 7 & 3.06 & 4 & 5.55 & 28 & 5.27 \\
\hline 10.2 & Neuromuscular disorders & 0 & 0 & 0 & 0 & 1 & 0.19 \\
\hline 11 & \multicolumn{7}{|l|}{ Eye } \\
\hline 11.6 & Treatment of glaucoma & 0 & 0 & 0 & 0 & 2 & 0.38 \\
\hline 12 & \multicolumn{7}{|l|}{ Ear, nose and throat } \\
\hline 12.2 & Drugs acting on the nose & 3 & 1.31 & 0 & 0 & 2 & 0.38 \\
\hline 13 & \multicolumn{7}{|l|}{ Skin } \\
\hline 13.4 & Topical corticosteroids & 0 & 0 & 0 & 0 & 3 & 0.56 \\
\hline 13.5 & Preparations for eczema and psoriasis & 0 & 0 & 0 & 0 & 1 & 0.19 \\
\hline 13.6 & Acne and rosacea & 0 & 0 & 0 & 0 & 1 & 0.19 \\
\hline
\end{tabular}

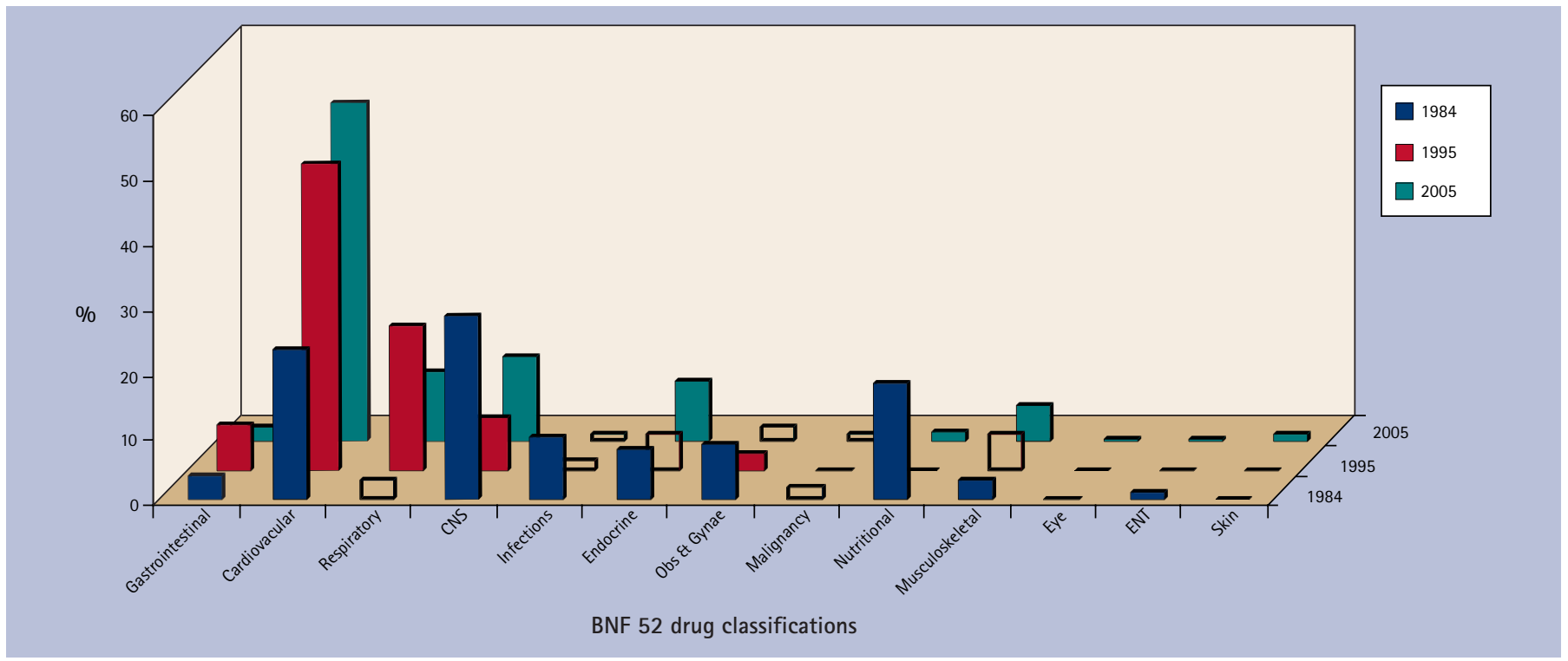

\section{Fig. 2 Type of medication taken (percentage)}

pertinent to point out that some drugs that dentists prescribe may produce severe adverse reactions when combined with concurrent medication - for example miconazole oral gel and metronidazole can dramatically increase the anticoagulant effect of warfarin. ${ }^{8,9}$ This can lead to haemorrhage. Awareness that such drug combinations should be avoided is essential for the safe practice of dentistry and illustrates the importance of an updated drug history. This study highlights the importance and relevance of teaching clinical pharmacology in the dental undergraduate curriculum. The need to maintain a contemporaneous knowledge of pharmacology and ready access to current reference sources which list drug interactions (such as the British National Formulary ${ }^{1}$ ), are essential to ensure the provision of safe dental care. 
1. British National Formulary 52. London: BMJ Publishing Group and RPS Publishing, September 2006. Available online at http://www.bnf.org/bnf/

2. Hemsley S M. Drug therapy in general practice. Br Dent J 1984; 157: 24

3. Daublander M, Muller R, Lipp M D. The incidence of complications associated with local anaesthesia in dentistry. Anesth Prog 1997; 44: 132-141.

4. Haskell R. Drug treatments affecting the management of dental patients. BrDent J 1975; 139: 249-251.

5. Shepherd R W. Drug treatment affecting the management of dental patients. Br Dent J 1976; 140: 20.
6. Meechan J G. Polypharmacy and dentistry: 1. Introduction and interactions with local anaesthetics and sedative drugs. Dent Update 2002; 29: 325-330.

7. Meechan J G. Polypharmacy and dentistry: 2. Interactions with analgesics and antimicrobials. Dent Update 2002; 29: 382-388.

8. Colquhoun M C, Daly M, Stewart P, Beeley L. Interaction between warfarin and miconazole oral gel. Lancet 1987; 1(8534): 695-696

9. Rice P J, Perry R J, Afzal Z, Stockley I H. Antibacterial prescribing and warfarin: a review Br Dent J 2003; 194: 411-415. 